\title{
Prosa pro Café
}

\section{Gabriel Travassos Araújo}

Recebido em: 16/09/2018

Aprovado em: 06/11/2019

DOI: $10.5965 / 2358092521222019133$

${ }^{1}$ Bacharel em Artes Visuais pela UFMS. E-mail: gabriel.araújo.1991@hotmail.com 


\section{RESUMO}

O artigo retrata a criação de uma intervenção Prosa Pro Café, que tem como proposta discutir e compreender as transformações em curso no campo social, captar o que já mudou e o que continua a mudar e a importância da interação entre os espectadores e a proposta final de uma produção artística em meio a valores, curiosidades e o cotidiano humano. 0 projeto foi desenvolvido para alcançar o entendimento desses aspectos na obra em questão utilizando uma metodologia de análise crítica e baseados nos conceitos de Arte Urbana e Arte Relacional apresentados por Marina Knapp, Paulo Souza, André Luiz Mesquita e Nicolas Bourriaud.

Palavras-chave: Intervenção artística; Arte relacional; Contemporaneidade.

\section{ABSTRACT}

The article portrays the creation of Prosa Pro Café intervention, which aims to discuss and understand the ongoing transformations in the social field, to capture what has already changed and what continues to change, and the importance of interaction between spectators and the final proposal of an artistic production in the midst of values, curiosities and human daily life. The project was developed to reach the understanding of these aspects in this project, using a methodology of critical analysis and based on the concepts of Urban Art and Relational Art presented by Marina Knapp, Paulo Souza, André Luiz Mesquita and Nicolas Bourriaud.

Keywords: Artistic intervention; Relational art; Contemporaneity. 
Esculturas em meio a praças, grafites, pinturas em edificações e performances pelas ruas da cidade, são exemplos de intervenções artísticas que tem como finalidade provocar nos espectadores uma (re)análise de suas ações diárias.

As intervenções artísticas podem ser caracterizadas por serem trabalhos produzidos em uma diversidade de materiais com, ao menos, um objetivo comum: chamar a atenção de quem as observa. Para que isso aconteça, as obras podem se utilizar de seu tamanho, como nos trabalhos de Christo e Claude (Figura 1), ou de sua natureza grotesca, como nas obras de Artur Barrio (Figura 2), dentre outras proposições estéticas. A intenção é que a curiosidade faça com que alguém invada esse espaço para estabelecer um diálogo.

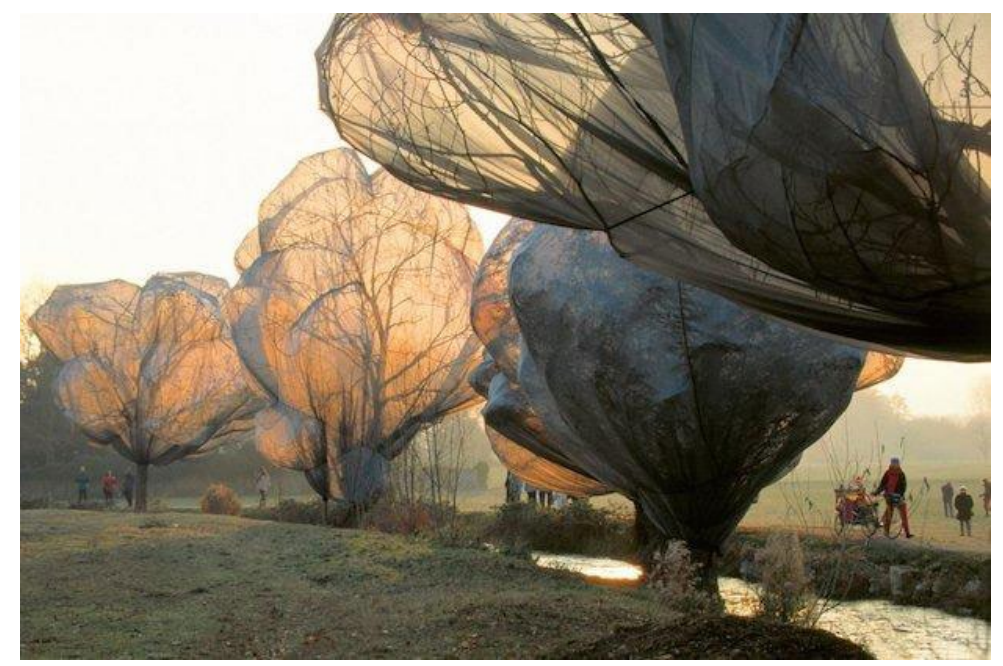

Figura 1: Árvores Embrulhadas, Christo and Jeanne-Claude, Beyeler and Berower Park, Riehen, Suiça, 1998.

Fonte: http://christojeanneclaude.net/projects/wrapped-trees\#.VwHTR_qwTU0 


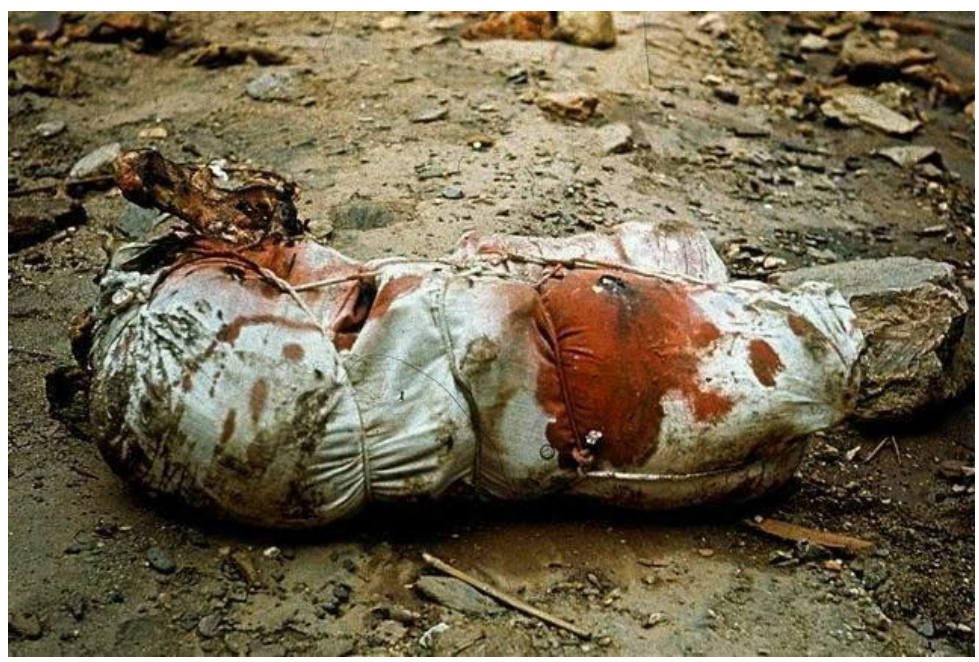

Figura 2: Trouxas Ensanguentadas, Artur Barrio, 1946.

Fonte: www.contramare.net/site/pt/the-political-meaning-of-artur-barrios-bloody-bundles/

Neste texto, tratarei de uma intervenção intitulada Prosa pro Café, realizada em 2015 pelo próprio autor, que teve como intuito, primeiramente, promover nos observadores uma análise sobre sua vida e seu cotidiano, estudar as diferentes reações para com a instalação, assim como, analisar a relação que as pessoas estabelecem com o inusitado no espaço urbano. Depois, desconstruir a ideia de arte que as pessoas têm, com a finalidade de trazê-la para lugares comuns na área da cidade, não a mantendo apenas em museus, assim como em outros espaços convencionais. Finalmente, fazer as pessoas pensarem sobre como a vida cotidiana é condicionada e limitada a certos acontecimentos além de incitar a transformação do olhar dos espectadores, dessa forma despertando no público olhares mais críticos e analíticos.

A metodologia utilizada é uma reflexão teórica e crítica sobre o processo e a execução da intervenção Prosa Pro Café baseadas nos conceitos de Arte Urbana e Arte Relacional. 


\title{
DIÁLOGOS ENTRE ARTISTA E PÚBLICO
}

Retornar à obra Prosa Pro Café com o intuito de refletir sobre essa experiência, fez-me perceber algo pertinente para a arte contemporânea, especialmente dentro das proposições de arte urbana: que a obra de arte se relaciona direta ou indiretamente com a sociedade por apresentar elementos que estão presentes nela. Como aponta Souza:

A Arte encontrada nas ruas, em seu diálogo com o público, é acessível a todas as pessoas porque tem elementos sensíveis na composição e permitem que qualquer pessoa possa entender e interpretar o que está ali, cada qual segundo o seu repertório e sem que a obra deixe de ser o que é. (SOUZA, 2014, p. 214)

Por meio dessa abertura ao diálogo, o artista é capaz de criar um vínculo com os espectadores e com elementos do cotidiano. Faz parte deste tipo de proposta criar momentos de encontro entre espectadores e obra, ou até mesmo entre espectadores e espectadores, ou espectadores e artista: as obras passam a ter uma característica relacional, cujo foco é o contexto das interações humanas defendido por Bourriaud:

\begin{abstract}
A "participação" do espectador, teorizada pelos happenings e pelas performances Fluxus, tornou-se uma constante na prática artística. O espaço de reflexão aberto pelo "coeficiente de arte" de Mareei Duchamp, que tenta delimitar exatamente o campo de intervenção do receptor na obra de arte, hoje consiste numa cultura interativa que apresenta a transitividade do objeto cultural como fato consumado. Com isso, esses elementos apenas corroboram uma evolução que ultrapassa largamente o domínio exclusivo da arte: é no conjunto dos vetores de comunicação que o grau de interatividade é ampliado. (BOURRIAUD, 1998, p. 12)
\end{abstract}

No caso da obra Prosa pro Café, em particular, optei por utilizar elementos que facilitassem a relação com a vida corrente das pessoas, que remetessem aos momentos cotidianos onde este importante contato humano pode ser resgatado: à mesa de 
alimentos, ao costume do diálogo, ao momento da refeição. O horário da refeição, em geral, representava o momento em que as pessoas se juntavam às suas famílias e amigos para, além de se alimentar, conversar, discutir e rir. No contexto atual, entretanto, o diálogo vem se tornando cada vez mais escasso; as pessoas tendem a guardar opiniões, sentimentos, de modo que as relações humanas têm sido substituídas pela impessoalidade das mídias digitais, uma vez em que as pessoas substituem as relações pessoais pelo uso das mídias, segundo o pesquisador e Médico Psiquiatra Augusto Cury (2014).

Nesse sentido, minha proposta de intervenção visava suscitar reflexões sobre essa realidade contemporânea em que acabamos ocupados demais com trabalho, dinheiro, família e nos esquecemos dos afetos, das conversas, daquilo que, acredito eu, faz-nos genuinamente humanos. Penso que quando o artista se vê em uma situação de cansaço existencial, que o prejudica ou que não o deixa satisfeito em relação à condição em que ele se encontra, ele se expressa artisticamente de forma a tentar mudar essa situação de descontentamento. O artista tem a liberdade de fazer isso de várias formas: críticas sociais, expondo seu ponto de vista, colocando em seus trabalhos estatísticas ou apurações reais de um determinado assunto, entre outros.

Segundo Bourriaud esse tipo de obra possui uma característica singular:

Uma obra de arte possui uma qualidade que a diferencia dos outros produtos das atividades humanas: essa qualidade é sua (relativa) transparência social. Uma boa obra de arte sempre pretende mais do que sua mera presença no espaço: ela se abre ao diálogo, à discussão, a essa forma de negociação inter-humana que Mareei Duchamp chamava de "o coeficiente de arte" - e que é um processo temporal, que se dá aqui e agora. Essa negociação se realiza numa "transparência" que caracteriza a obra de arte como produto do trabalho humano: de fato ela mostra (ou sugere) seu processo de fabricação e produção, sua posição no jogo das trocas, o lugar - ou a função - que atribui ao espectador, e, por fim, o comportamento criador do artista (isto é, a sucessão de atitudes e gestos que compõem seu trabalho e que cada obra 
individual reproduz, como se fosse uma amostra ou ponto de referência). (BOURRIAUD, 1998, p. 12)

Após chamar a atenção dos espectadores por meio de elementos facilmente identificáveis, decidi, em um segundo momento, criar uma conexão visual despertando o interesse por meio de formas, tamanhos e lugares. Como a intervenção propõe uma interferência em um espaço onde ela não seria esperada, optei por realizar minha intervenção em frente ao restaurante da Universidade Federal de Mato Grosso do Sul, durante o horário de almoço assim causando um impacto sobre os espectadores. Sobre esta característica de inferência no cotidiano da obra urbana, Knapp coloca que:

As intervenções artísticas não são autorizadas, não têm fins lucrativos e não visam o marketing. Por meio destas é permitido expressar o pensamento íntegro do artista, sem preocupar-se com outras linguagens. Desta forma está intrínseco em sua existência o caráter polêmico desta linguagem. Ainda que haja a interrupção do fluxo urbano ao deparar-se com estas proposições artísticas, o contato com o ambiente urbano pode ser mais significativo se existir o olhar pesquisador, que problematiza o que é visto. (KNAPP, 2011, p. 13).

Entendo, portanto, que a arte pode refletir questões que estão postas na sociedade. Por meio de sua percepção sobre o mundo, o artista pode expor à sociedade situações que demandam reflexão (como, no caso desta obra o cansaço existencial) em suas mais variadas formas. Segundo Souza, podemos identificar que os artistas:

[...] compreendem suas relações com a estrutura do mundo por meio da Arte. Nesse contexto as descrições carregam possibilidades de luta e resistência, a percepção das ideologias responsáveis pelo cansaço existencial, o suporte fundamental da memória e a descoberta dos instrumentos e caminhos para não se submeter à opressão (SOUZA, 2014, p. 202). 
Em Prosa Pro Café, desse modo, busquei estimular os espectadores a pausarem seu cotidiano e sentarem para um café visando, a princípio, chamar a atenção devido ao tamanho e forma da Instalação. Escolhi representar uma mesa de café da manhã gigante onde o artista e os espectadores ficam em cima.

A ideia principal era deslocar a percepção dos espectadores do cotidiano, a fim de que eles invadissem esse espaço para interagir com a obra e com o artista como propõe a arte relacional. Paralelamente mostrando a realidade de como não mantemos comunicação/diálogo ao longo dos nossos dias, devido a múltiplos fatores, tais como trabalho, compromissos, reuniões e afins.

No tópico a seguir, tratarei de expor os modos como a intervenção artística foi encaminhada, desde a concepção da escultura até sua instalação e performance, bem como refletir sobre sua recepção e a reverberação desse trabalho na minha maneira de ver a escultura na contemporaneidade.

\section{DESENVOLVIMENTO DA OBRA E A INSTALA- ÇÃO/INTERVENÇÃO}

O trabalho proposto teve por objetivo convidar os observadores a participar da obra, com a finalidade de que eles interferissem nela de forma livre. A intenção era utilizar um momento do cotidiano que todas as pessoas, ou que a maioria delas, identifica como "a hora do café" para realizar a intervenção. Os artistas e coletivos analisados no texto de André Luiz Mesquita também apresentam características similares a obra em questão:

Como uma alternativa de ação concreta e espontânea ao espaço físico, aos rótulos e parâmetros convencionais das instituições de arte, a intervenção urbana problematiza o contexto em que é realizada, questiona a autonomia de um trabalho artístico e dialoga com o entorno ou uma situação social. (MESQUITA, 1990, p.220)

Muitas pessoas têm o costume de parar um momento do seu trabalho para tomar um café, "bater um papo", relaxar e 
até as pessoas que não consomem café, entendem o que esse momento representa.

O plano inicial era construir esculturas que chamariam atenção por formarem uma "grande mesa de café" com a intenção de convidar as pessoas que estavam de passagem a parar, entrar na obra e interagir com ela. O ambiente seria construído sobre um grande tapete quadriculado de forma retangular em preto e branco que demarcaria a mesa do café (Figura 3).

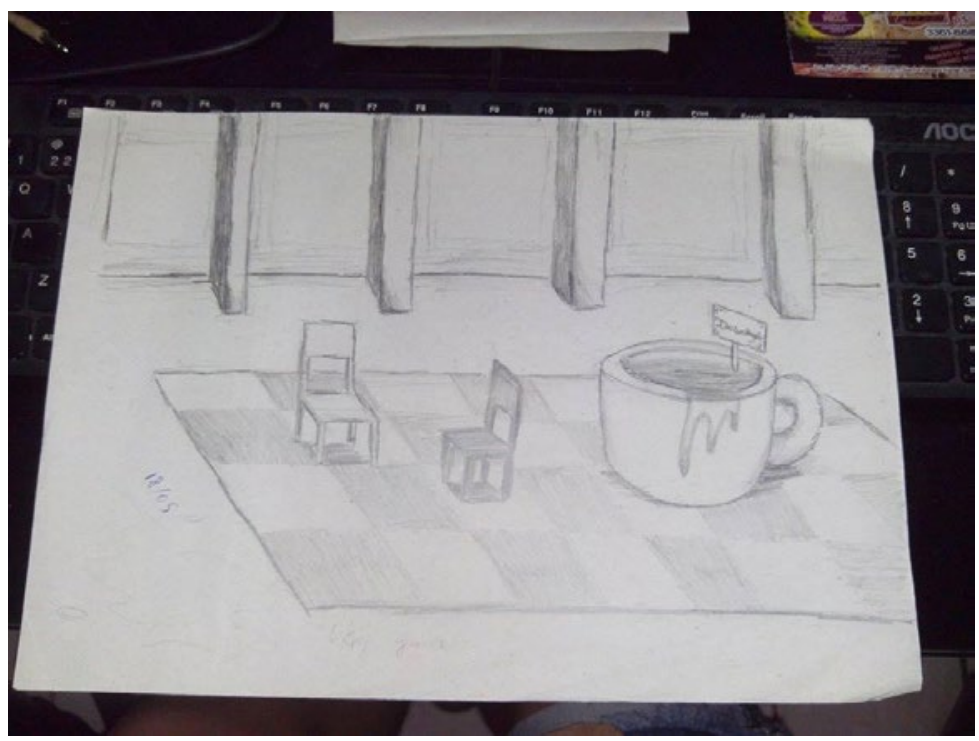

Figura 3: Rascunho da proposta.

Fonte: Do autor (2015)

O primeiro desafio foi a pesquisa de materiais. Para a escultura da xícara, pesquisei materiais que poderiam ter um preço acessível, pois a dimensão da escultura deveria ser de aproximadamente $1 \mathrm{~m} 3$ (metro cúbico). Para a toalha de mesa, comprei dois tipos de malhas de $3 \mathrm{~m}$ (metros) cada uma, que chegaram a $6 \mathrm{~m}$ (metros) de comprimento e largura no total. 
Depois de escolher o isopor, comecei a talha experimentando as ferramentas e as estudando. $\mathrm{O}$ isopor é fácil de ser manuseado, por ser leve, é mais rápido de esculpir. Em torno de dois dias, o bloco possuía sua forma. Escolhi revestir a peça com massa corrida por ser um produto de fácil acesso e rápido resultado (Figura 4).

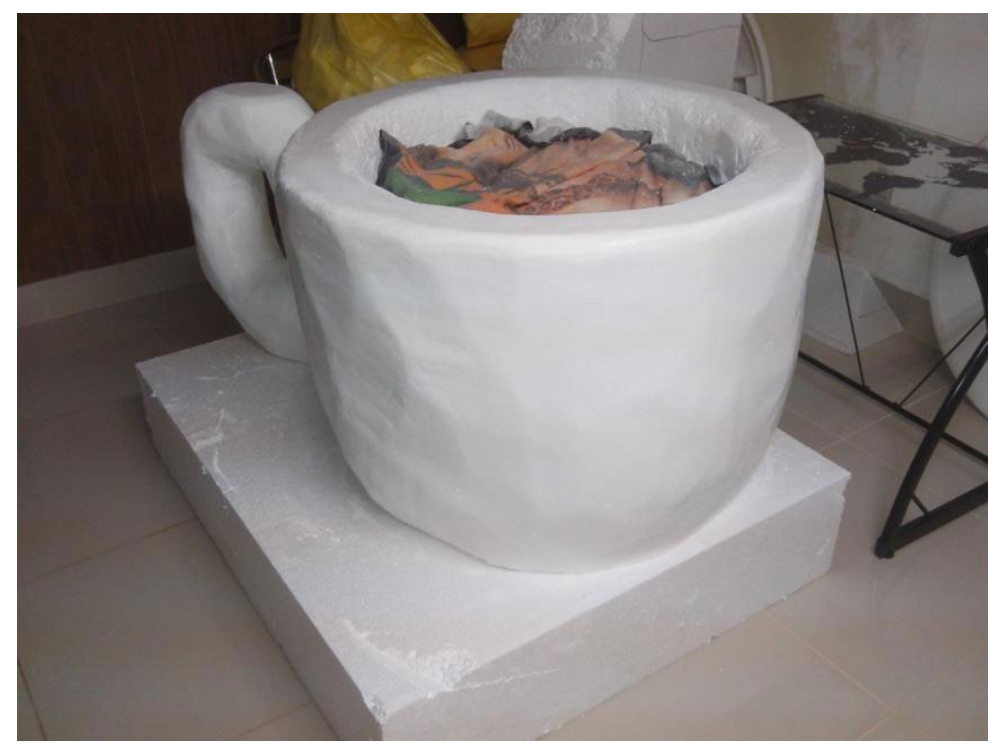

Figura 4: Escultura revestida com massa corrida.

Fonte: Do autor (2015)

Para pintar sobre a peça, utilizei tinta acrílica branca. Após a pintura com a tinta branca, revesti o interior da xícara com gesso para ter um aspecto de líquido. O líquido dentro da xícara seria o café, que foi pintado de cor preta (Figura 5). Finalmente, inseri alguns detalhes, almejando atingir um efeito de brilho, os quais foram feitos com giz branco e preto. 


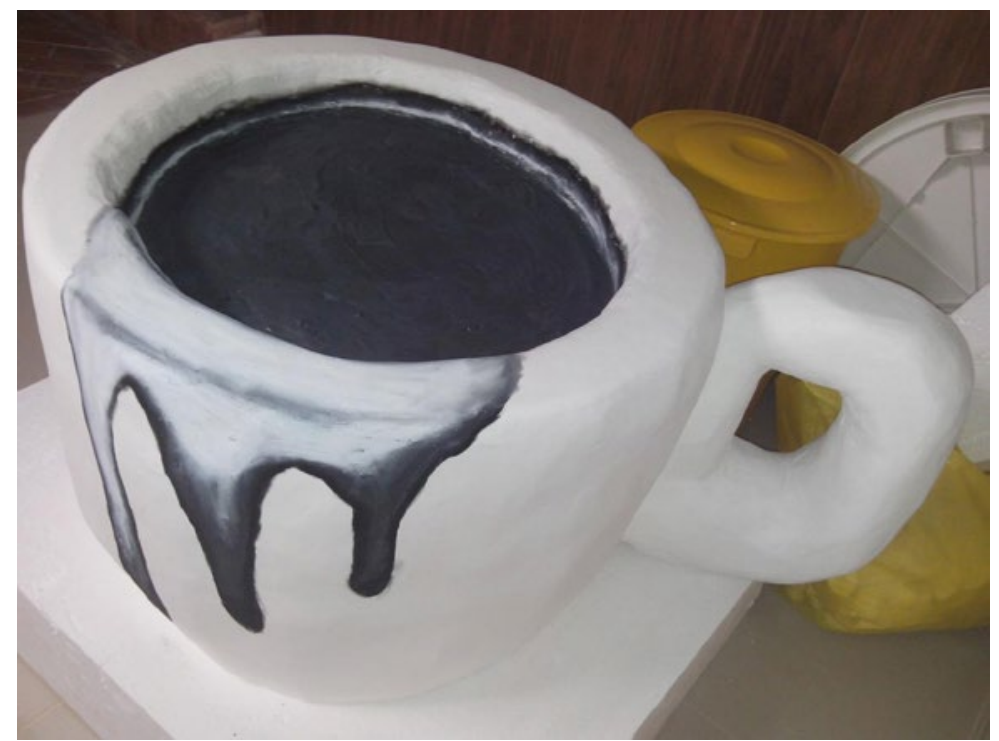

Figura 5: Fase de detalhamento da pintura.

Fonte: Do autor (2015)

No dia 20 de maio de 2015, às 9 horas da manhã, o trabalho foi devidamente instalado na frente do restaurante universitário da UFMS - Universidade Federal de Mato Grosso do Sul. Como eu também faria parte da obra através de uma performance relacional, eu escolhi vestir uma roupa que se relacionasse com ela. Optei por vestir roupas totalmente brancas seguindo a cor predominante da obra. A cor branca faz conexão com a cor de uma folha em branco, ou algo inacabado, vazio. Essa era a cor predominante, pois após todo o processo de diálogo, os participantes deixariam escritas na obra, preenchendo-a (Figura 6). Como as minhas roupas eram brancas e eu me propus a fazer parte da obra, um participante escreveu, inclusive, sobre a minha roupa. Toda a exposição foi um momento de grande expectativa para mim, pois a forma com que os espectadores agiriam, era inesperada. Por meio do conceito de performance decidi participar desta obra pois, segundo Mesquita, a performance é 
A performance (ou o que Victor Turner denomina de "reflexividade performativa") cria uma condição na qual um grupo sociocultural reflete obre si mesmo, sobre suas relações, ações, símbolos, significados, códigos, posições, estatutos, estruturas sociais, papéis éticos e legais e outros componentes socioculturais que constituem os seus "eus" públicos. (MESQUITA, 1990, p. 220).

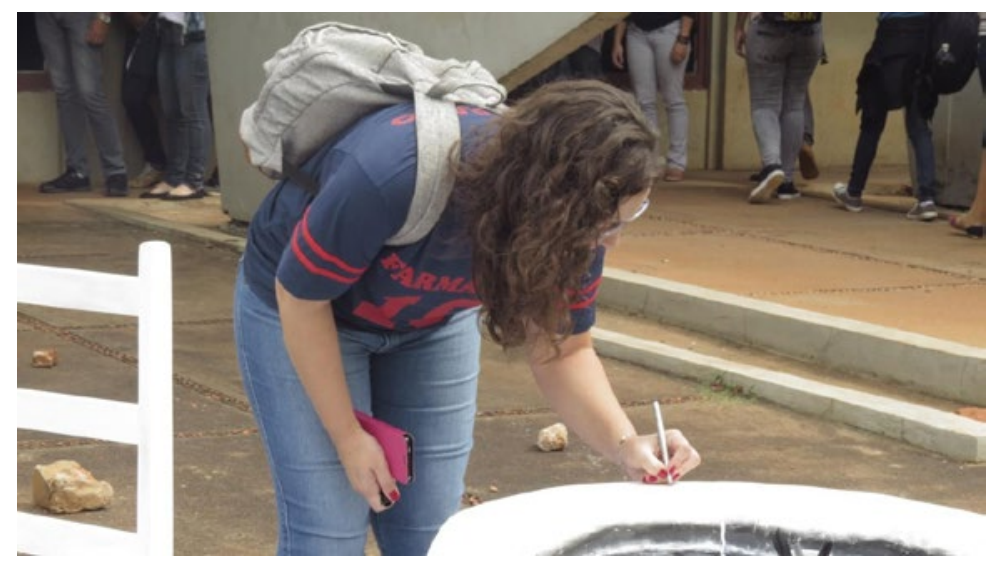

Figura 6: Participante escrevendo sobre a escultura.

Fonte: Do autor (2015)

O projeto atraiu olhares, causando reações positivas e negativas na maioria das pessoas que estavam passando por aquele ambiente até que, finalmente, várias pessoas começaram a interagir com a obra. Um dos pontos de extasia da exposição foi o momento em que uma grande quantidade de pessoas formou uma roda de conversa em que assuntos diversos eram discutidos (Figura 07).

O olhar, o interesse, as reações dos espectadores foram de grande importância para analisar o trabalho, pois transformou aquele tempo de intervenção em um espaço de reflexão sobre os modos como reagimos à arte que acontece nas ruas, como nos relacionamos com diferentes opiniões sobre um assunto, além de ter sido uma oportunidade de compartilharmos 
sentimentos e ideias. Por meio destas reações e interações de caráter relacional a obra se concretizou e atingiu o objetivo de estreitar relações interpessoais.

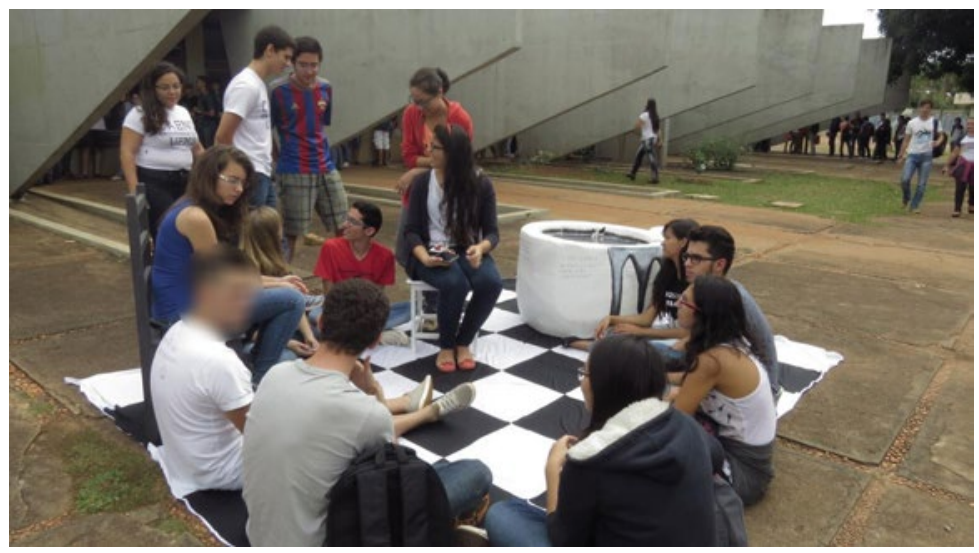

Figura 7: Momento durante a intervenção.

Fonte: Do autor (2015)

\section{CONSIDERAÇÕES FINAIS}

Após esta pesquisa bibliográfica acerca dos aspectos relacionais das intervenções urbanas, pude perceber alguns pontos de interesse que são comuns em propostas de diferentes artistas dentro desse espectro conceitual. Esses interesses se dão, em grande parte, em apontar, evidenciar e criar situações de tensão com o cotidiano, com o intuito de chamar a atenção dos espectadores. Alguns projetos analisados por Mesquita (1990) também enfatizam a importância da análise que deve ser feita sobre a relação entre o ser humano e a sociedade, além do papel que a arte possui nesse contexto.

Durante a montagem da obra Prosa Pro Café, no período que antecedia a abertura do Restaurante Universitário - RU, eu me sentia muito apreensivo. A incerteza das reações que a pro- 
posta poderia causar nas pessoas me trazia uma grande insegurança. Depois que o RU abriu, o sentimento de ansiedade só aumentava. Finalmente uma pessoa resolveu adentrar o espaço da intervenção e interagir com a obra. A partir daí, o sentimento de apreensão foi mudando e eu fui ficando mais tranquilo e, dessa forma, pude focar mais em como melhorar minha desenvoltura para chamar a atenção dos observadores curiosos.

Ao final do período que a intervenção esteve montada, fiquei muito satisfeito com o resultado da proposta. Para tornar a intervenção mais capaz de transmitir uma diversidade maior de sentimentos, eu me inseri na obra, a fim de torná-la mais humana. Pude concluir, a partir das conversas que surgiram, que muitas pessoas compartilham de ideias e similaridades relacionadas ao meio em que vivemos e ao nosso cotidiano.

Por fim, concluí que o resultado da intervenção foi bastante satisfatório, atingindo e superando as minhas expectativas iniciais e as proposições conceituais apresentadas nos textos de Mesquita (1990), Bourriaud (1998), Souza (2014) e Knapp (2011) diretamente ligados aos aspectos da arte urbana e da arte relacional, além de chamar a atenção dos espectadores, dar pausa no cotidiano, gerar questionamentos e, finalmente, gerar interações entre os participantes e desses com a obra.

Sempre acreditei na arte e na capacidade da transformação por meio dela. Durante a trajetória universitária, fui desenvolvendo um gosto particular pelas peculiaridades da arte intervencionista e acreditando no poder de transformação gerado pelas relações entre a obra, o artista e o público.

Considero, por fim, que a arte deva ocupar espaços públicos proporcionando novos ângulos de visão, oportunizando a fruição estética e o debate sobre temas sociais importantes. Penso que é importante compreender e fazer uma leitura mais crítica da sociedade na qual vivemos e que essas ações são possíveis por meio da arte, se a arte estiver de forma acessível e inserida no cotidiano. 


\section{REFERÊNCIAS}

BOURRIAUD, Nicolas. Estética Relacional. Dijon: Martins, 1998.

CURY, Augusto. "Ansiedade, Como Enfrentar o Mal do Século": A síndrome do pensamento Acelerado: como e porque a humanidade adoeceu coletivamente, das crianças aos adultos. Augusto Cury. 1. ed. São Paulo: Saraiva, 2014

KNAPP, Marina. Intervenções Artísticas no Espaço da Cidade: Provocações e Possibilidades Educativas, Porto Alegre, 2011. Disponível em < http://www.lume.ufrgs.br/bitstream/ handle/10183/36795/000818688.pdf?sequenc> Acesso em: 12 de maio de 2015

SOUZA, Paulo C. A. O mundano e o promíscuo na arte latinoamericana: a prática social de pintores populares, 2014. 320f. Tese (Doutorado em Educação). Centro de Educação e Ciências Humanas, Universidade Federal de São Carlos, São Carlos, 2014.

MESQUITA, André Luiz. Insurgências Poéticas: Arte Ativista e Ação Coletiva. 1990. 429 f. Dissertação (Mestrado) - Curso de Pós-graduação em História, Faculdade de Filosofia, Letras e Ciências Humanas, Universidade de São Paulo, São Paulo, 2000. 